\title{
PENCEGAHAN HIPERTENSI DALAM RANGKA UPAYA PENINGKATAN KESEHATAN DESA CIBATOK 1
}

\author{
Rachma Hidana ${ }^{1}$, Amelia Adriana ${ }^{2}$ \\ rachma.hidana@uika-bogor.ac.id ${ }^{1}$ \\ Anurholihah@gmail.com ${ }^{2}$ \\ Dosen Fakultas Ilmu Kesehatan ${ }^{1}$, Mahasiswa KKN Kelompok 24 Tahun $2018^{2}$
}

\begin{abstract}
ABSTRAK
Hipertensi merupakan kondisi yang sering ditemukan pada pelayanan kesehatan primer. Peningkatan tekanan darah yang berlangsung dalam jangka waktu lama (persisten dapat menimbulkan kerusakan pada ginjal (gagal ginjal), jantung (penyakit jantun koroner) dan otak (menyebabkan stroke). Pencegahan hipertensi dapat dilakukan bila seseorang mengetahui siapa saja yang bisa menjadi Faktor resiko dari hipertensi. Oleh karena itu, partisipasi semua pihak baik dokter dari berbagai bidang peminatan hipertensi, pemerintah, swasta maupun masyarakat diperlukan agar hipertensi dapat dikendalikan. Keberhasilan pelaksanaan pembangunan kesehatan sangat dipengaruhi oleh pendekatan kebijakan, dan strategi program yang tepat serta sasaran yang jelas.
\end{abstract}

\section{Kata Kunci : pencegahan, hipertensi, faktor resiko, kesehatan}

\section{PENDAHULUAN}

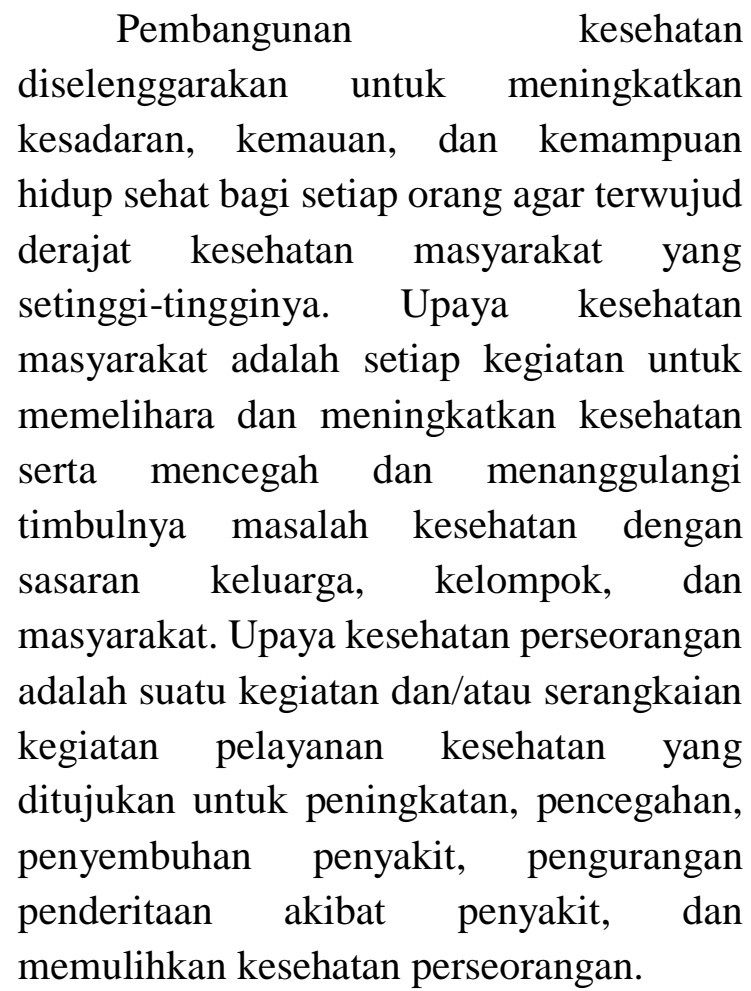

Hipertensi atau tekanan darah tinggi adalah peningkatan tekanan darah sistoli lebih dari $140 \mathrm{mmHg}$ dan tekanan darah diastolik lebih dari $90 \mathrm{mmHg}$ pada dua kal pengukuran dengan selang waktu lima menit dalam keadaan cukup istirahat/tenang. Hipertensi masih merupakan tantangan besar di Indonesia. Angka prevalensi yang masih tinggi, yaitu sebesar 25,8\%, sesuai data Riskesdas 2013 dan meningkat 30,9\% di tahun 2016. Di Jakarta tahun 2013 angka Hipertensi mencapai 20\%, angka itu lebih rendah dibandingkan dengan Jawa Jawa Barat yang angka prevalensinya adalah $30 \%$. Salah satu penyebabnya adalah tingkat pengetahuan masyarakat dan upaya pencegahan hipertensi yang masih kurang. Hal ini didukung oleh penelitian yang dilakukan oleh Prasetiyo,2013 dalam hasil penelitiannya menyebutkan bahwa 
pengetahuan masyarakat tentang hipertensi adalah $48,7 \%$ dan upaya pencegahan kekambuhan hanya 43,6\%. Oleh sebab itu KKN UIKA 24 di desa cibatok 1 cibungbulang kabupaten bogor melakukan seminar dan pelatihan pencegahan hipertensi dengan sasaran para ibu-ibu yang masih sangat awam dan usianya lebih dari 25 tahun.

\section{Keadaan Geografis}

Kecamatan Cibungbulang adalah merupakan Wilayah Pembangunan Barat bersama 12 (dua belas) Kecamatan lainnya dengan Pusat Pertumbuhan Utama Kecamatan Jasinga, Parung Panjang dan Leuwiliang. Pusat Pertumbuhan Sekunder adalah Kecamatan Ciampea dan Tenjo serta selebihnya merupakan Pusat Pertumbuhan Tersier termasuk Kecamatan Cibungbulang.

Kecamatan Cibungbulang merupakan salah satu Kecamatan di wilayah Barat Kabupaten Bogor dengan luas wilayah 3.266.158 Ha berbatasan sebagai berikut :

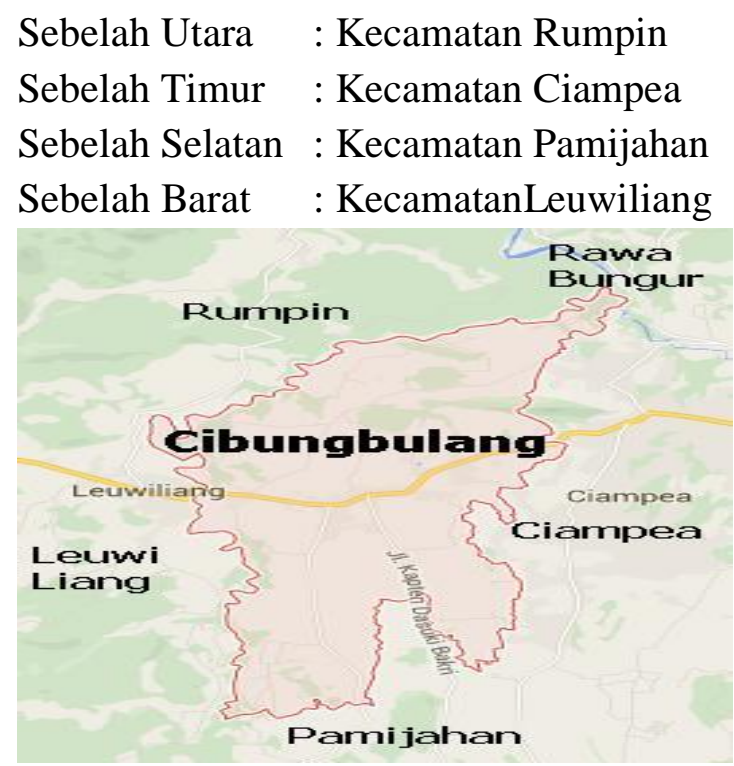

Ketinggian dari permukaan laut $350 \mathrm{~m}$ dengan suhu maksimum $31^{\circ} \mathrm{C}$ dan minimum $15^{\circ} \mathrm{C}$ serta curah hujan rata-rata antara $2000-3000 \mathrm{~mm}$.
Ditinjau dari segi Tofografi wilayah sangat berfariasi yaitu berupa daerah pegunungan bagian Timur, dataran rendah disebelah Barat. Sungai-sungai yang berada di Kecamatan Cibungbulang posisinya membentang, mengalir dari daerah Utara ke Selatan dan terdapat sebanyak 5 (Lima) Daerah Aliran Sungai (DAS) yaitu DAS Cibungbulang, DAS Cianten, DAS Cigamea, DAS Cikampeni. Sungai-sungai pada DAS tersebut mempunyai peranan yang sangat penting dan strategis sebagai sumber air dan irigasi.

Sebagaimana RENSTRA Kabupaten Bogor Tahun 2008-2014, Kecamatan Cibungbulang termasuk salah satu wilayah pembangunan Bogor Barat dengan strategi pembangunan Perwilayahan Percepatan dan sebagai pusat pertumbuhan tersier yang merupakan simpul-simpul pengembangan pertanian dan agrobisnis / industri serta jasa perdagangan, yang diharapkan dapat mendongkrak Index Pembangunan Manusia (IPM) dari sisi komponen ekonomi masyarakat.

\section{Kondisi Masyarakat}

Desa cibatok 1 terdapat 2 (dua) posyandu yang diselenggarakan setiap hari selasa dan rabu pada minggu kedua tiap bulannya. Disela-sela posyandu ada petugas kesehatan yang memberikan berbagai penyuluhan dan informasi kesehatan terkait dengan bayi dan balita. Para masyarakat cibatok 1 sangat aktif dan antusias dengan pelaksanaan posyandu tersebut. Selain itu ada juga 1 (satu) posyandu lansia yang aktif melakukan pemeriksaan kesehatan lansia.

Mahasiswa kkn 24 melakukan kegiatan periksa tensi gratis tiap hari kamis di mushola Al-ikhlas untuk mengetahui keadaan tekanan darah pada ibu-ibu pengajian dan puncaknya dilakukan seminar dan pelatihan pencegahan 
hipertensi pada tanggal 30 September 2018

pukul 09.00-11.30 WIB.

\section{METODOLOGI}

Tahapan pelaksanaan untuk kegiatan ini sebagaimana terlihat pada bagan sebagai berikut:

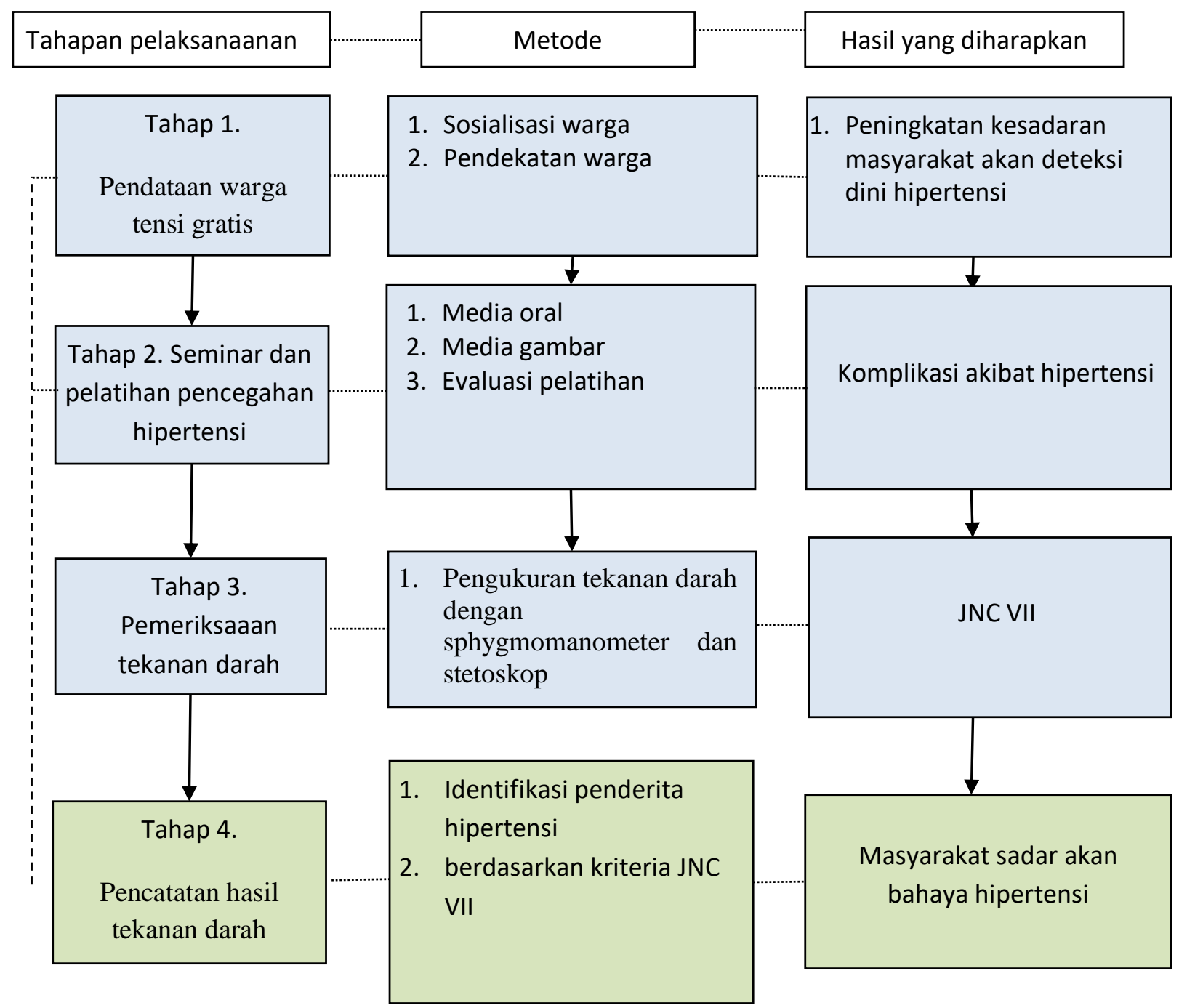

\section{Jadwal Kegiatan}

\begin{tabular}{|c|l|c|c|c|c|}
\hline \multirow{2}{*}{ No. } & \multicolumn{1}{|c|}{ Kegiatan } & \multicolumn{3}{|l|}{ Minggu } \\
\cline { 3 - 6 } & & $\mathbf{1}$ & $\mathbf{2}$ & $\mathbf{3}$ & $\mathbf{4}$ \\
\hline 1 & Penyusunan Rencana kegiatan & & & & \\
\hline 2 & Sosialisasi rencana kegiatan & & & & \\
\hline 3 & Pendataan warga tensi gratis & & & & \\
\hline 4 & Seminar dan Pelatihan tentang hipertensi & & & & \\
\hline 5 & Pemeriksaan tekanan darah & & & & \\
\end{tabular}




\begin{tabular}{|c|l|l|l|l|}
\hline 6 & Pencatatan hasil pengukuran tekanan darah & & & \\
\hline 7 & Monitoring dan evaluasi & & & \\
\hline 8 & Penyusunan laporan & & & \\
\hline
\end{tabular}

\section{Metode Pendekatan}

Pendekatan yang digunakan dalam kegiatan ini adalah:

1. Pendekatan perorangan yaitu penyelenggara langsung berhubungan atau bertatap muka dengan sasaran. Antara lain : kunjungan rumah, pertemuan di balai warga, pertemuan ibu-ibu PKK, pertemuan di posyandu.

2. Pendekatan kelompok yaitu petugas berhubungan dengan sekelompok sasaran. Antara lain : pertemuan dengan para perangkat desa.

3. Penyuluhan merupakan suatu kegiatan pemecahan masalah pada tema tertentu yang telah ditetapkan yang melibatkan para pakar, biasanya dari perguruantinggi sebagai pembawa makalah atau pembanding atau penyanggah. Tujuannya adalah menyampaikan suatu pendapat atau sesuatu yang baru untuk dikembang tumbuhkan menjadi sesuatu yang lebih luas lagi kepada yang lainnya.

4. Pendidikan/pelatihan merupakan upaya untuk pengembangan terhadap Sumber Daya Manusia, terutama untuk pengembangan aspek kemampuan intelektual dan kepribadian manusia (Notoadmodjo, 2015).

\section{Partisipasi Masyarakat dalam Pelaksanaan Program}

Partisipasi masyarakat yang dapat dilakukan dalam kegiatan ini adalah sebagai berikut:

1. Mempersiapkan masyarakat yang bersedia untuk dilakukan pemeriksaan tekanan darah
2. Menuliskan data secara lengkap dengan cara anamnesa secara singkat

3. Mempersiapkan tempat yang akan digunakan untuk pelaksanaan pemeriksaan tekanan darah.

4. Seminar singkat tentang hipertensi dan pencegahannya

5. Pelatihan bagaimana cara pencegahan hipertensi.

6. Pelaksanaan pemeriksaan pengukuran tekanan darah

7. Masyarakat ikut berperan dalam menyukseskan program kesehatan yang telah diselenggarakan

\section{Langkah Evaluasi}

Evaluasi yang akan dilakukan terdiri dari:

1. Evaluasi proses, yang terkait dengan perencanaan, pelaksanaan dan monitoring kegiatan. Evaluasi proses akan dilakukan setiap pekan bersama dengan masyarakat.

2. Evaluasi hasil, yang akan dilaksanakan setelah kegiatan dilaksanakan. Evaluasi hasil ditujukan untuk menguji pemahaman masyarakat akan pentingnya pemeriksaan pengukuran tekanan darah secara berkala untuk mendeteksi adakah peningkatan tekanan darah sedini mungkin sehingga tidak berdampak pada komplikasi yang lebih membahayakan.

\section{Evaluasi dampak}

a. Meningkatkan pengetahuan masyarakat akan penyakit hipertensi dan pencegahannya

b. Mendorong bagi masyarakat yang sudah menderita hipertensi supaya dapat mencegah terjadinya komplikasi. 
c. Mengajarkan masyarakat untuk bergaya hidup sehat dengan mengurangi factor resiko

d. Meningkatkan kesadaran masyarakat akan pemeriksaan pengukuran tekanan darah secara berkala minimal 1 bulan sekali.
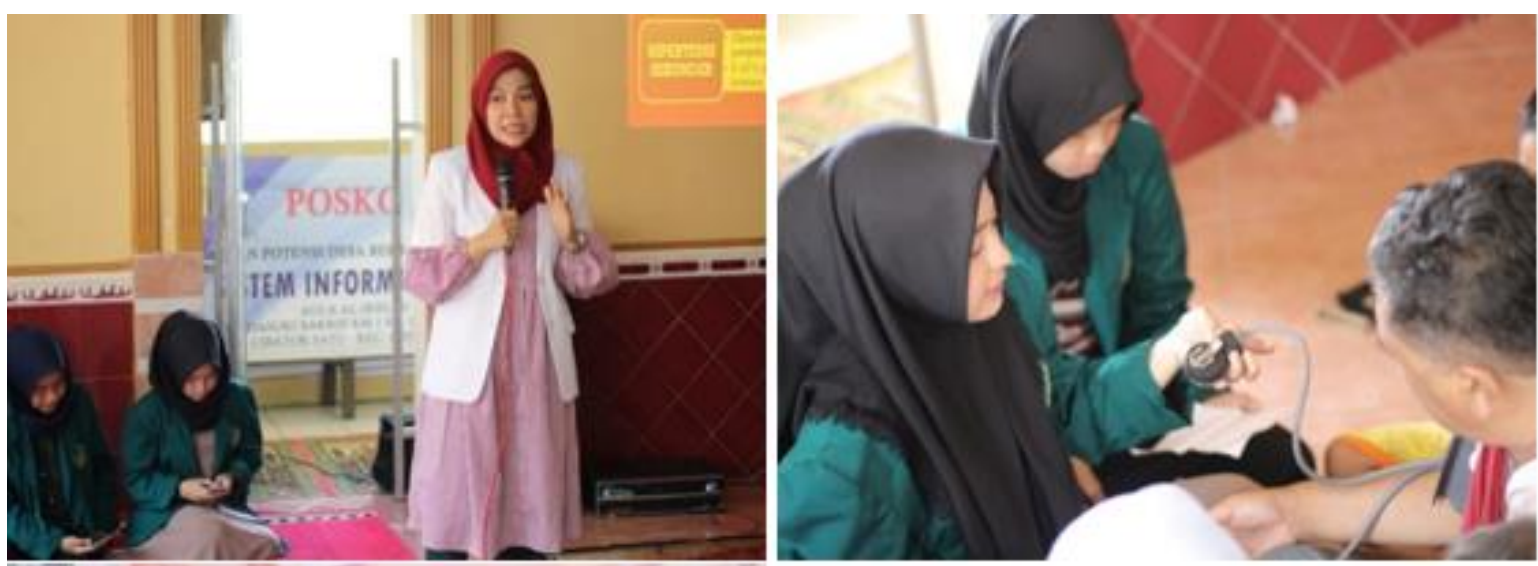

Dalam pelaksanaan kegiatan $\mathrm{KKN}$ Tematik Terintegrasi Universitas Ibn Khaldun Bogor di Desa Cibatok 1, Kecamatan Cibungbulang, Kabupaten Bogor. Kegiatan Penyuluhan dan pelatihan Pencegahan hipertensi diawali dengan pemeriksaan tensi gratis secara rutin yang dilakukan setiap hari Kamis setelah pengajian di Mushola Al-Ikhlas. Dengan dibantu para kader dan petugas kesehatan di sekitar wilayah tugas KKN 24 maka kegiatan penyuluhan dan pelatihan berjalan lancar.

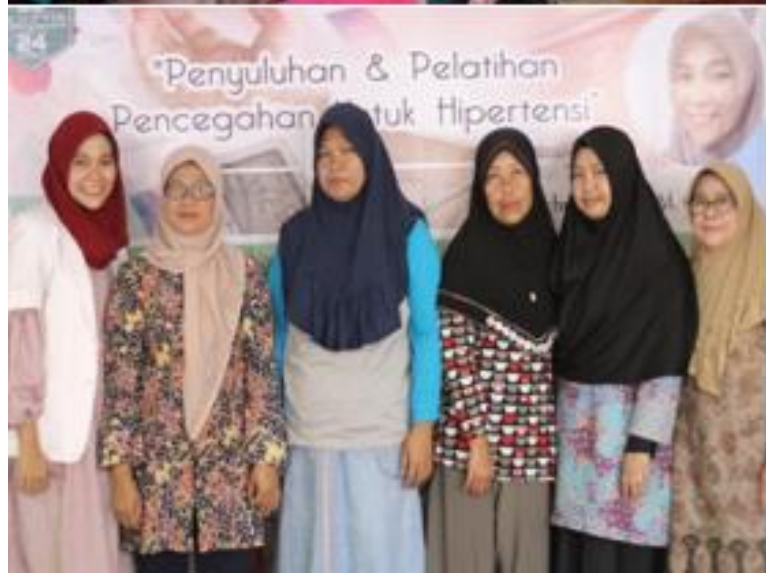

Foto kegiatan Penyuluhan dan pelatihan pencegahan hipertensi 


\section{KESIMPULAN}

Hipertensi atau tekanan darah tinggi adalah peningkatan tekanan darah sistoli lebih dari $140 \mathrm{mmHg}$ dan tekanan darah diastolik lebih dari $90 \mathrm{mmHg}$ pada dua kal pengukuran dengan selang waktu lima menit dalam keadaan cukup istirahat/tenang. Peningkatan tekanan darah yang berlangsung dalam jangka waktu lama (persisten dapat menimbulkan kerusakan pada ginjal (gagal ginjal), jantung (penyakit jantung koroner) dan otak (menyebabkan stroke) bila tidak dideteksi secara dini dan mendapat pengobatan yang memadai. Pencegahan hipertensi dapat dilakukan bila seseorang mengetahui siapa saja yang bisa menjadi Faktor resiko dari hipertensi.

Kuliah Kerja Nyata adalah bagian dari sistem Pendidikan Tinggi yang menempatkan mahasiswa di luar kampus agar mahasiswa hidup ditengah - tengah masyarakat bersama masyarakat untuk membantu dan mendampingi masyarakat memanfaatkan potensi sumber daya alam lokal dan sumber daya manusia yang ada untuk mengatasi permasalah masyarakat dalam kurun waktu tertentu. Tim KKN Posko 24 di tempatkan di Desa Cibatok 1 kecamatan Cibungbulang Kabupaten Bogor.

Seminar dan pelatihan pencegahan hipertensi ini dilakukan pada hari Kamis, 30 Agustus 2018 yang diawali dengan pemaparan dan pelatihan pencegahan. Pada akhir sesi dilakukan pengukuran tensimeter dan didapatkan data dimana 50\% menderita hipertensi dan $50 \%$ tidak hipertensi. Itu merupakan angka yang sangat tinggi.

\section{SARAN}

Hipertensi merupakan penyakit
peningkatan tekanan darah dengan
komplikasi yang bisa menyebabkan
peningkatan morbiditas dan mortalitas.
Diharapkan kedepannya ada pembentukan
TIM kader kesehatan yang peduli akan
penyakit hipertensi. Sehingga pemeriksaan
pengukuran tekanan darah ini bisa terus
berjalan secara rutin meskipun kegiatan
KKN ini telah selesai dilaksanakan yaitu
selama 30 hari.
selama 30 hari. 


\section{REFERENSI}

Romadon, Deni. (2017). Profil Desa

Cibatok 1 Kecamatan Cibungbulang Kabupaten Bogor. Kabupaten Bogor: Profil data

Kemenkes. (2014). Infodatin Pusat Data dan Informasi Kementrian Kesehatan RI. Jakarta: Kemenkes

Kemenkes. (2017). Profil Kesehatan Indonesia 2017. Jakarta : Kementerian Kesehatan RI. 2017
Notoatmodjo. (2015). Metodologi Penelitian Kesehatan. Jakarta: Rineka Cipta

Petunjuk Pelaksanaan KKN Tematik Terintegrasi 2018, LPPM UIKA BOGOR 2018, UIKA Press

Prasetiyo. (2013). Hubungan tingkat Pengetahuan Tentang Hipertensi dengan Upaya Pencegahan Kekambuhan Hipertensi Pada Lansia Di desa Blulukan Kecamatan Colomadu Kabupaten Karanganyar. Surakarta : UMS 